\title{
X. Account of a work entitled 'Storia de' Fenomeni del Vesuvio avvenuti negli anni 1821, 1822, e parte del 1823," etc. "History of the Phœnomena of vesuvius during the years 1821,1822, and part of 1823; accompanied with observations and experiments.
}

\section{J. Monticelli , M. Menard de la Groye \& N. Covelli}

To cite this article: J. Monticelli , M. Menard de la Groye \& N. Covelli (1824) X. Account of a work entitled 'Storia de' Fenomeni del Vesuvio avvenuti negli anni 1821, 1822, e parte del 1823," etc. "History of the Phœnomena of vesuvius during the years 1821, 1822, and part of 1823; accompanied with observations and experiments., Philosophical Magazine Series 1, 63:309, 46-50, DOI: $10.1080 / 14786442408644463$

To link to this article: http://dx.doi.org/10.1080/14786442408644463

Published online: 29 Jul 2009.

Submit your article to this journal $\sqsubset$

山 Article views: 2 
produced on the animals on board, already mentioned, as well as by the circumstance of a great number of men being attacked after the ship was cleared at Gibraltar, and till she arrived in a more northern latitude.

It may be considered out of place here, to give any detail of the curative means employed. I shall therefore only briefly state that sulphur given in large quantities internally, produced no alleviation of the symptoms; on the contrary, it greatly augmented the bowel complaints, with which many of the men were affected, and brought on a most severe tenesmus; consequently, it was laid aside; applied externally, it was of no use.

The only plan which produced effectual relief was removal from the ship, with the frequent use of small doses of neutral salts and detergent gargles.

W. BunnetT.

X. Account of a Work entitled "Storia de' Fenomeni del Vesuvio avvenuti negli anni 1821, 1822, e parte del 1823," etc. "History of the Phanomena of Vesuzius during the Years 1821, 1822, and Part of 1823; accompanied with Observations and Experiments. By J. Monticelir, Perpetual Secretary of the Royal Acudemy of Sciences of Naples; and N. CoveLLI, of the Royal Institute of Encouragement." By M. Menard de la Groye*.

THE general form of this work is nearly that of a journal, that is to say, the facts are recited in the natural and successive order in which they were collected. If we judge of the ultimate celebrity of M. Monticelli, by that which he has for several years enjoyed, arising from his former labours, we shall be induced to believe that he will occupy the first rank among the historians of this celebrated volcano, which we always consider as in some sort a volcanic archetype.

'The new work which we announce was preceded by a description of the eruptions of 1812 and 1817 . The same author likewise published in French, in conjunction with M. Covelli, some "Observations and Experiments made at Vesuvius during Part of the Years 1821 and 1822."-(See Bulletin, tom. ii. p. 435.) The first section of the work which now occupies our attention, is for the most part a repetition,

* From the Bulletin des Annonces Scientifiques, tom. iv. p. 34. M. dc la Groye's analysis of the former work by MM. Monticelli and Covelli ahove alluded to by him, will be found in vol. lxii. of the Philosophical Magazine, p. 90. 
in Italian, of that just mentioned. The new eruption in the month of October last, not only one of the most considerable which have occurred since that so celebrated in 1794, but even of the grandest which have ever been witnessed, having presented to the authors an extensive field for new experiments and observations, induced them to resume and enlarge that work by the addition of two sections, a preface, a table of contents, and figures.

The most remarkable of the principal facts contained in this work, are enumerated by the authors themselves in the preface. These are the formation of earthy pisolites among the pulverulent lava; the particular and oblique ejection of a fine sand, or, as it is vularly named, volcanic ashes, which also produces small and extremely singular currents, having at a distance the appearance of streams of hot water; that of other currents formed entirely of substances much more bulky, but equally incoherent; the examination made with new and peculiar interest of the discontinuance or intermission, and of the partial fits of the eruptions, which are compared by the authors to the paroxysms of violent diseases; the positive observation of sulphurous acid, and of sulphur itself, in the lava which has ceased flowing; that of carbonic acid in fumeroles of lava, before it is completely cold, and especially of a considerable evolution of this acid, after great eruptions, giving place to large and numerous mofettes which are manifested around the base of the mountain. This fact is so remakable and of such importance, that the celebrated Sir Humphry Davy thought that it might lead to the discovery of the origin of the various calcareous rocks in which volcanic substances are contained, either in cavities or in the substance of the rocks themselves.

Among the newly recognised productions of Vesuvius, will be remarked the sulphates and chlorides of manganese, which characterize a number of saline metallic sublimates, and the existence of which in the mineral kingdom has been hitherto unknown. This work likewise offers several considerations concerning the diversity of temperature, which the different volcanic vapours require in order to their attaining a solid state. The veracity of Pliny the younger, in the description he gives of the eruption which occasioned his uncle's death, has been frequently questioned; but MM. Monticelli and Covelli prove, by comparing several passages of his relation with the effects which they have themselves observed, that he is entitled to complete confidence. 'They have also observed the formation of the last cone, and seen it gradually disappear in part, in the same manner as that which, according to the description of Strabo, 
existed before the horrible catastrophe of the year 79. The first section is entitled "The State of Vesuvius from the Eruption of 1820 and 1821 to the Commencement of October 1822; with Observations and Experiments." It contains an article on the state of the volcano from the 11th of May 1822 to the beginning of October, not inserted in the work which preceded it; from which it also differs in some other respects towards the end. The second section is a "Journal of the Eruption of October 1822." The authors first speak of the state of the atmosphere during the spring, summer, and autumn which preceded that eruption; a state rendered more remarkable by the excessive drought which prevailed. They mention some movements of the volcano precursory to the eruption; and then proceed to the description of the phænomena observed in the interval between the 21 st of October and the 11th of November; during which time occurred the various paroxysms of that eruption. The zigzag lightning began to appear on the $22 \mathrm{~d}$, at two o'clock in the afternoon, not proceeding from the pine of ashes, or from the great cloud of smoke arising from it, but in a part of the atmosphere between both and occupied only by the ashes. The lightning was not accompanied with any detonation. This electric phænomenon, which increased as the violence of the eruption diminished, did not take place in the middle of a paroxysm, but at the edges of the clouds of ashes. At a later period the lightning was seen to emanate not only from the dusky clouds or the air, but also from the earth, and even to traverse the roads.

Our authors discovered, by very simple but decisive experiments, that the falling cinders were strongly and vitreously electrified. Electric discharges were still seen from the summit of the mountain; and the cinders, which were at first gray, notwithstanding that their electricity remained the same, altered to brown, and finally became of a reddish colour. These red ashes falling in great abundance, and spreading themselves thickly to a considerable distance, caused great darkness. In addition to this, they observed a strong smell of muriatic acid and of muriate of iron, which reached as far as Naples: had this not been the case, they would yet have discovered from other effects the existence of this acid in the ashes, which had the same day been the subject of their experiments.

The pine presented a variety and a remarkable mutability of colours, which are attributed by the authors to the refractions produced in the different currents of air through which they passed. After an abundant shower of rain and cinders, 
the trunk of this pine, already much weakened from other circumstances, instead of the cylindrical column presented only a series of large and small globes, which the authors attribute, in great measure, to the enfeebled state of the electric attraction of the air. At the conclusion of the eruption the volcano attracted to itself all the clouds of the atmosphere, from which was formed an immense quantity of water, which rolling down its sides in torrents, and carrying with it large quantities of incoherent matter, devastated the surrounding country. Of the pisolites, some of them, and those the largest, fell already formed; the others were formed upon the ashes which covered the ground by means of a fine rain.

Section 3d. "Observations and Experiments made during the Eruption of October 1822." 'This section is the longest, the most interesting, and contains the greatest variety of new facts. The following are the titles of its principal divisions:

Art. I. "Periods of the Maximum and Minimum of Violence which this Eruption presented. In this is given in detail the fact that the paroxysms appear subject to this general law, that their violence is in the inverse ratio to their duration. The shortest and most terrible are in the middle of the eruption; the longest and feeblest, at its commencement and at its close.

Art. II. "State of the Crater and of the great Cone on the 16th of November 1822.-Description of the Cone and of the actual Crater." 'The Atrio became more and more filled up, and Vesuvius, properly so called, and Mount Somma were approaching to union. The edge of the crater in question was very narrow.

The authors have given in this part a review of the observations made upon the height of Vesuvius from the year 1749 to 1822 .

Art. III. "Examination of the Substances which are ejected or produced during the Eruption." These are divided into five classes: 1 . incoherent solids; 2. liquids; 3. volatile substances; 4. gaseous substances; 5 . imponderable substances. Each of these classes is examined separately and in detail, and the various modes and periods of their appearance are pointed out. The ashes have been carried as far as 105 miles in almost all directions; and the strata which are the result of them, as well as those consisting of other incoherent matter, are studied under various aspects, and are observed to differ greatly from those formed by alluvial deposition. The effects of these showers of ashes on organized bodies are again spoken of. The currents of lava form subVol. 63. No. 309. Jan. 1824. 
jects of consideration in the article on liquid substances. Water is an important agent, mechanically and chemically, among those of a volatile nature. Among the gaseous substances, muriatic acid is evolved at all periods of the eruption, and at all temperatures.

Art. IV. Of the Currents of incoherent Lava.

Art. V. Of the Currents of Ashes.

Art. VI. Of the Aggregates formed by those Substances.

Art. VII. Of the Mofette produced by the Carbonic Acid.

Art. VIII. Of Obsidian, a rare Species of Lava at Vesuvius.

In Art. IX. is given A Catalogue of the Products of the Eruption of October 1822 : In Art. X. the Details of the chemical Processes, which they followed in their Analytical Examination of the Substances produced in this last Eruption.

Art. XII. contains two tables of Meteorological Observations made during the months of October and November 1822, at the Observatory of Naples, at the distance of about eight miles from Vesuvius. It also contains a recapitulation of the most remarkable facts observed in the course of the last eruption, and since that period.

The figures represent, 1st, Vesuvius viewed from the road of the Hermitage a few days before the eruption of October $1822 ; 2 \mathrm{~d}$, this eruption observed from the same situation at eight in the evening; 3d, the Volcano seen from Bosco-treCase; 4th, a drawing of the Crater made upon the spot, on the 16 th of November 1822.

XI. On the ensuing Opposition of Mars. By F. BaILY, Esq. F.R.S. Read before the Astronomical Society of London, January 9, 1824.*

A T a time when we have two new and excellent observaA tories established in the southern hemisphere, where the eelestial phænomena are watched and observed with the greatest diligence and zeal, it becomes the more important and necessary that corresponding observations of a certain class of those phænomena, of not very frequent occurrence, should also be made in the northern hemisphere, by such persons as are fortunately possessed of the requisite means for this purpose. Without this co-operation, the labours of those industrious observers will lose much of their value, and the advantageous opportunity of elucidating an important

* See our report of the proceedings of the Society at page 61 . branch 